\title{
Quality of DOTS Adherence Counselling among Hospitalized Tuberculosis Patients
}

\author{
Shikongo IN Taati, Francis Kalemeera, Dan Kibuule* \\ School of Pharmacy, Faculty of Health Sciences, University of Namibia, Windhoek, Namibia \\ Email: taatishikongo@gmail.com, fkalemeera@unam.na, *dkibuule@unam.na
}

How to cite this paper: Taati, S.I., Kalemeera, F. and Kibuule, D. (2019) Quality of DOTS Adherence Counselling among Hospitalized Tuberculosis Patients. Journal of Tuberculosis Research, 7, 77-94. https://doi.org/10.4236/jtr.2019.72008

Received: March 7, 2019

Accepted: June 27, 2019

Published: June 30, 2019

Copyright (c) 2019 by author(s) and Scientific Research Publishing Inc. This work is licensed under the Creative Commons Attribution International License (CC BY 4.0).

http://creativecommons.org/licenses/by/4.0/ (c) (i) Open Access

\begin{abstract}
Setting: Non-adherence to tuberculosis treatment is a risk factor for multidrug-resistant tuberculosis (MDR-TB). In 2015, 480,000 cases of MDR-TB were notified worldwide, leading to 250,000 deaths. Aim: The quality of the Directly Observed Treatment (DOT) adherence counselling among patients with drug resistant and sensitive was assessed. Methods: A hospital based crossectional analytical study was conducted at the national TB hospital in Windhoek among patients with MDR-TB and drug susceptible TB (DS-TB). The quality of adherence counselling was assessed against the WHO counselling guidelines using an interviewer-administered questionnaire. Quality was measured by completeness, duration and frequency of the adherence counselling sessions or program as well as patient satisfaction and preferences. Quantitative and qualitative data were by descriptive statistics in SPSS v23 and thematic analysis respectively. Results: Of the 50 patients, $60 \%$ were male, $76 \%$ were aged $<45$ years and $92 \%$ perceived the direct observation of TB treatment as good or excellent. Only $40 \%$ of the patients received DOT adherence counselling over the last three months and $16 \%$ had not received counselling since admissions. The patient-related factors affecting the quality of DOT adherence counselling were forgetfulness (22\%) and/or treatment cessation upon feeling better (12\%), limited access to DOT services in the community versus the health facility and lack of individual versus group counselling as well as comprehension of languages and messages used during counselling. Conclusions: The quality of DOT adherence counselling among hospitalized TB patients is sub-optimal. There is need for a standard operating procedure and guidelines for effective adherence counselling among TB patients to optimize treatment outcomes.
\end{abstract}

\section{Keywords}

Quality, Dots, Adherence Counselling, Namibia 


\section{Introduction}

The burden of drug resistant tuberculosis is a major global public health concern affecting 117 countries [1] [2]. In 2015, the World Health Organisation (WHO), reported 480,000 new cases of multidrug-resistant TB (MDR-TB, i.e. to tuberculosis resistant to two key first line drugs, isoniazid and rifampicin) and 100,000 cases of rifampicin-resistant TB (RR-TB), which led to 250,000 deaths world-wide [3]. Namibia is a high TB burden country and the country notified 137 new cases of MDR-TB and 199 cases of RR-TB in 2014 [4] [5]. The Ministry of Health and Social Services (MoHSS) of Namibia estimates the cost for treating a case of MDR-TB at $\$ 5100$ compared to $\$ 100$ for a patient with drug susceptible TB (DS-TB) [5]. This is a concern for most resource-limited countries in sub-Saharan Africa whose health budgets are constrained by the double burden of HIV [5] [6].

Nevertheless, in 1996 the Government of Namibia implemented WHO's DOTS (direct observed treatment short-course) strategy at all the public health facilities [5] [7] [8]. The DOTS programme included observation of administration of standardized short-course TB medicines under direct and supportive observation [9] [10]. However, the global scale up of DOTS is coincided with an increase in the incidence of MDR-TB [11] [12]. Non-adherence to treatment among TB cases with drug susceptible $\mathrm{TB}$ is a major risk factor for the development of DR-TB which extremely difficult and expensive to treat [12] [13] [14]. Treatment of MDR-TB is associated with a long treatment period of up-to 18 months, poor adherence rates and outcomes [15] [16] [17]. Moreover, the lack of adherence counselling as well as emotional and psychosocial support to TB patients and their families is linked to poor treatment outcomes including loss to follow-up and development of DR-TB [5] [18] [19]. The occurrence of adverse drug effects is more common among patients medication for DR-TB and DS-TB, which compromises adherence to medication [18] [20] [21] [22]. Thus, the World Health Organisation (WHO) identifies improved quality of adherence counselling as a key intervention under DOTS to improve medication adherence and TB treatment of outcomes [23] [24]. Indeed, a study among prisoners, showed that adherence counselling improved treatment completion from $12 \%$ to $24 \%$ [25] [26].

Consequently, the aim of this study was to determine the quality of adherence counselling among hospitalized TB patients with MDR-TB and DS-TB to provide policy guidance on strengthening DOTS programmes and improve outcomes.

\section{Methods and Materials}

\subsection{Study Design and Population}

A hospital based crossectional analytical study design used quantitative methods of data collection to determine the quality of adherence counselling among cases of MDR-TB and DS-TB receiving care at Katutura State Hospital, the national referral TB hospital for Namibia. The target population comprise hospitalized patients treated for DR-TB (Drug-resistant Tuberculosis) and DS-TB (Drug-susceptible 
Tuberculosis). The study included all the 25 DR-TB patients admitted at the hospital at the time of the study (i.e. April to June 2018). Subsequently, a sample of 25 patients hospitalized with DS-TB were selected using simple randomly sampling. The determination of the sample size was informed by the maximum bed-capacity for DR-TB cases (i.e. 25 beds) and the acquisition of a written informed consent to participate in the study. The study excluded all patients at the private health facilities as well as those at any public health facility that is not Katutura State Hospital.

\subsection{Data Collection Procedure}

The data on quality of adherence counselling was collected MDR-TB and DS-TB patients using interviewer-administered questionnaires (Annexure B) that consisted of 26 questions. The tool was piloted on 5 patients with DR-TB and standardized as well as translated in local two languages, Oshiwambo and Afrikaans, during the interviews by the researcher (TS). The data were subsequently entered in Epidata v3.1 for management (checked thoroughly for completion and errors and then stored securely).

\subsection{Data Analysis}

The main outcome variables were the level of perceived quality of adherence counselling (i.e. satisfaction with counselling, comprehensiveness, time spent on counselling and the frequency) and associated factors (i.e. patient and health system related factors). Quantitative data were exported to SPSS v 23 for quantitative analysis. The quality of adherence counselling was measured based on indicators (i.e. timing, duration, frequency and satisfaction) as well as patient awareness of good DOT adherence counselling and practices, patient-related factors and hospital-related factors that affect the quality of DOTS Adherence counselling. The factors associated with the quality of DOT adherence counselling were analysed using descriptive statistics and an association was made using chi-squared and t-test. The level of significance for both tests was set at $95 \%$ confidence interval with a level of alpha at 0.5 .

\subsection{Ethical Considerations}

Ethical clearance was obtained from the research and ethics review board (REC) of the Ministry of Health and Social Services as well as from the Katutura Intermediate Hospital. In addition, each patient freely volunteered to participate in the study and the patients were given a written and verbal detailed explanation of the study (Annexure A). Patient confidentiality was upheld at all times and patient indicators and private details such as their names were not disclosed.

\section{Results}

\subsection{Socio-Demographic Characteristics of the Patients}

Fifty tuberculosis patients participated in the study, yielding a response rate of 
$63 \%(50 / 80)$. Of the 50 participants, $60 \%(\mathrm{n}=30)$ were male and $77 \%$ were aged 45 years or younger. Majority of the participants $(66 \%)$ had attained at least a secondary education. The number of respondents with multi-drug resistant TB (MDR, $n=25$ ) was equal to those with drug-susceptible TB (DST-TB) patients (Table 1). There were no significant differences between the sociodemographic characteristics of patients with MDR and drug susceptible tuberculosis ( $p>0.05)$ (Table 1).

\subsection{Patient Practices and Perceptions on the Quality of DOTS Adherence Counselling}

Of the 50 patients, the majority (56\%) felt that their adherence would improve at home as opposed to being in the $\mathrm{TB}$ clinic. The main reasons for non-adherence to TB medication and/or DOT appointments were forgetfulness (22\%) and seizing treatment upon feeling healthier (12\%) (Table 2). In addition, patients perceived improved qualities of DOT adherence counselling to include; individual counselling sessions (74\%), an adherence counsellor of the same sex (16\%) and/or age category (12\%) (Table 2). There were no significant differences in the factors associated with adherence counselling among patients with MDR and DST tuberculosis ( $\mathrm{p}>0.05)$ (Table 2).

\subsection{Hospital Related Factors Affecting Quality of DOT Adherence}

Of the 50 patients, $92 \%(n=46)$ confirmed that the stipulated schedule for DOT

Table 1. Social-demographic characteristics of key informants $(n=50)$.

\begin{tabular}{|c|c|c|c|c|}
\hline & \multirow{2}{*}{ Total (\%) } & \multicolumn{2}{|c|}{ Type of patient } & \multirow{2}{*}{ p-value } \\
\hline & & MDR-TB (\%) & DST-TB (\%) & \\
\hline All cases & 50 & $25(50 \%)$ & $25(50 \%)$ & \\
\hline \multicolumn{5}{|l|}{ Sex of } \\
\hline Male & $30(60 \%)$ & $16(53.3 \%)$ & $14(46.7 \%)$ & 0.564 \\
\hline Female & $20(40 \%)$ & $9(45 \%)$ & $11(55 \%)$ & \\
\hline \multicolumn{5}{|l|}{ Age } \\
\hline $18-25$ & $9(18 \%)$ & $4(44.4 \%)$ & $5(55.6 \%)$ & \\
\hline $26-35$ & $19(38 \%)$ & $11(57.9 \%)$ & $8(42.1 \%)$ & \\
\hline $36-45$ & $10(20 \%)$ & $6(60 \%)$ & $4(40 \%)$ & 0.552 \\
\hline $46-55$ & $6(12 \%)$ & $3(50 \%)$ & $3(50 \%)$ & \\
\hline $56-65$ & $4(8 \%)$ & $1(25 \%)$ & $3(75 \%)$ & \\
\hline$>66$ & $2(4 \%)$ & $0(4 \%)$ & $2(100 \%)$ & \\
\hline \multicolumn{5}{|c|}{ Education Level } \\
\hline None & $4(8 \%)$ & $2(50 \%)$ & $2(50 \%)$ & \\
\hline Primary & $13(26 \%)$ & $7(53.8 \%)$ & $6(46.2 \%)$ & 0.709 \\
\hline Secondary & $29(58 \%)$ & $13(44.8 \%)$ & $16(55.2 \%)$ & \\
\hline Tertiary & $4(8 \%)$ & $3(75 \%)$ & $1(25 \%)$ & \\
\hline
\end{tabular}

MDR-TB = Multi-Drug Resistant Tuberculosis, DS-TB = Drug-Susceptible Tuberculosis. 
Table 2. Factors associated with the quality of DOTS adherence counselling.

\begin{tabular}{|c|c|c|c|c|}
\hline & $\begin{array}{c}\text { Total } \\
(n=50)\end{array}$ & $\begin{array}{l}\text { MDR-TB } \\
(\mathrm{n}=25)\end{array}$ & $\begin{array}{c}\text { DS-TB } \\
(n=25)\end{array}$ & p-value \\
\hline \multicolumn{5}{|l|}{ Forgetfulness } \\
\hline Yes & $11(22 \%)$ & $3(27.3 \%)$ & $8(72.7 \%)$ & \multirow[t]{2}{*}{0.088} \\
\hline No & $39(78 \%)$ & $22(56.4 \%)$ & $17(78 \%)$ & \\
\hline \multicolumn{5}{|l|}{ Feeling of remission } \\
\hline Yes & $6(12 \%)$ & $3(50 \%)$ & $3(50 \%)$ & \multirow[t]{2}{*}{1.000} \\
\hline No & $44(88 \%)$ & $22(50 \%)$ & $22(50 \%)$ & \\
\hline \multicolumn{5}{|l|}{ Adherence at Home } \\
\hline Yes & $28(56 \%)$ & $14(50 \%)$ & $14(50 \%)$ & \multirow[t]{2}{*}{1.000} \\
\hline No & $22(44 \%)$ & $11(50 \%)$ & $11(50 \%)$ & \\
\hline \multicolumn{5}{|c|}{ Preference of Group sessions vs individual } \\
\hline Individually & $37(74 \%)$ & $16(43.2 \%)$ & $21(56.8 \%)$ & \multirow[t]{2}{*}{0.107} \\
\hline In groups & $13(26 \%)$ & $9(69.2 \%)$ & $4(30.8 \%)$ & \\
\hline \multicolumn{5}{|c|}{ Preference of Counsellor's Sex } \\
\hline Yes & $7(14 \%)$ & $4(57.1 \%)$ & $3(14 \%)$ & \multirow{3}{*}{0.538} \\
\hline No & $1(2 \%)$ & $1(100 \%)$ & $0(0 \%)$ & \\
\hline Gender is Irrelevant & $42(84 \%)$ & $20(47.6 \%)$ & $22(52.4 \%)$ & \\
\hline \multicolumn{5}{|c|}{ Preference of counsellor's age } \\
\hline Younger than you & $3(6 \%)$ & $0(0 \%)$ & $3(100 \%)$ & \multirow{4}{*}{0.261} \\
\hline The same age as you & $3(6 \%)$ & $2(66.7 \%)$ & $1(33.3 \%)$ & \\
\hline Older than you & $6(12 \%)$ & $4(66.7 \%)$ & $2(33.3 \%)$ & \\
\hline The age is irrelevant & $38(76 \%)$ & $19(50 \%)$ & $19(50 \%)$ & \\
\hline
\end{tabular}

was consistent majority of the time and $76 \%$ of the patients found the scheduled time to be convenient. In addition, $80 \%$ of the patients were counselled in a language that they understood, however $16 \%$ were however not counselled at all since having been admitted (Table 3 ). In addition, $16 \%$ of the patients found the counsellors to be judgmental, while $74 \%$ felt that the counsellors created a comfortable and free environment (Table 3). There were significant differences in the hospital factors associated with adherence counselling among patients with DST and MDR tuberculosis ( $\mathrm{p}>0.05$ ).

\subsection{Indicators for Measuring the Quality of D0T Adherence}

Of the total patients that partook in the study, $32 \%$ knew what DOT is and while $26 \%$ of patients knew what MDR-TB is, only $2 \%$ knew how it arises (Table 4 ). About $88 \%$ of the patients were however aware that TB is curable and $96 \%$ of them had faith in the possibility of treatment success. Furthermore, $26 \%$ percent of the participants felt that a few missed doses or more is insignificant towards precipitating treatment failure (Table 4). 
Of the 50 patients, $82 \%(\mathrm{n}=41)$ received DOT daily at consistent times, $36 \%$ $(\mathrm{n}=18)$ of the patients received adherence counselling at least 1 month ago or earlier whilst $16 \%(8 / 50)$ were never counselled at all. Of the $84 \%$ of patients that had received adherence counselling, $74 \%$ had counselling sessions that were at least 5 minutes long (Table 4, Figure 1).

Table 3. Frequency and percentage of hospital related factors.

\begin{tabular}{|c|c|c|c|c|}
\hline & $\begin{array}{c}\text { Total } \\
(n=50)\end{array}$ & $\begin{array}{c}\text { MDR-TB } \\
(\mathrm{n}=25)\end{array}$ & $\begin{array}{c}\text { DS-TB } \\
(\mathrm{n}=25)\end{array}$ & P-value \\
\hline \multicolumn{5}{|c|}{ DOT Schedule consistency } \\
\hline Yes & $46(92 \%)$ & $23(50 \%)$ & $23(50 \%)$ & \multirow[t]{2}{*}{1.000} \\
\hline No & $4(8 \%)$ & $2(50 \%)$ & $2(50 \%)$ & \\
\hline \multicolumn{5}{|c|}{ DOT Schedule Convenience } \\
\hline Yes & $38(76 \%)$ & $20(52.6 \%)$ & $18(47.4 \%)$ & \multirow[t]{2}{*}{0.508} \\
\hline No & $12(24 \%)$ & $5(41.7 \%)$ & $7(58.3 \%)$ & \\
\hline \multicolumn{5}{|l|}{ Language Used } \\
\hline Yes & $40(80 \%)$ & $20(50 \%)$ & $20(50 \%)$ & \multirow{3}{*}{1.000} \\
\hline No & $2(4 \%)$ & $1(50 \%)$ & $1(50 \%)$ & \\
\hline Not Applicable & $8(16 \%)$ & $4(50 \%)$ & $4(50 \%)$ & \\
\hline \multicolumn{5}{|c|}{ Judgemental Counsellors } \\
\hline Yes & $8(16 \%)$ & $6(75 \%)$ & $2(25 \%)$ & \multirow{3}{*}{0.291} \\
\hline No & $34(68 \%)$ & $15(44.1 \%)$ & $19(55.9 \%)$ & \\
\hline Not Applicable & $8(16 \%)$ & $4(50 \%)$ & $4(50 \%)$ & \\
\hline \multicolumn{5}{|c|}{ Comfortable Environment } \\
\hline Yes & $37(74 \%)$ & $18(48.6 \%)$ & $19(51.4 \%)$ & \multirow{2}{*}{0.893} \\
\hline No & $5(10 \%)$ & $3(60 \%)$ & $2(40 \%)$ & \\
\hline Not Applicable & $8(16 \% 0$ & $4(50 \%)$ & $4(50 \%)$ & \\
\hline
\end{tabular}

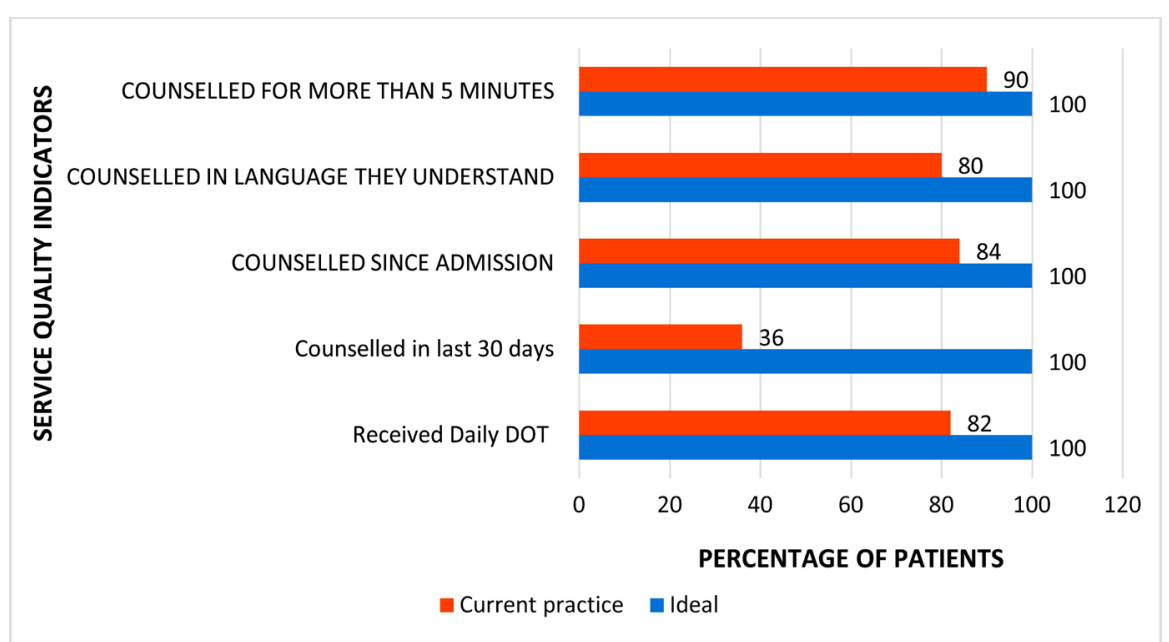

Figure 1. Quality of DOT and adherence counselling services indicators. 
Table 4. Frequency and percentage of Indicators for measuring the quality of DOT adherence.

\begin{tabular}{|c|c|c|c|c|}
\hline Indicator of DOT quality & Total & MDR-TB $(n=25)$ & DS-TB $(n=25)$ & P-value \\
\hline \multicolumn{5}{|l|}{ Patient knows DOT definition } \\
\hline Yes & $16(32 \%)$ & $9(56.3 \%)$ & $7(43.8 \%)$ & \multirow[t]{2}{*}{0.544} \\
\hline No & $34(68 \%)$ & $16(47.1 \%)$ & $18(52.9 \%)$ & \\
\hline \multicolumn{5}{|l|}{ DOT frequency } \\
\hline At each dose & $41(82 \%)$ & $21(51.2 \%)$ & $20(48.8 \%)$ & \multirow{4}{*}{0.388} \\
\hline At most doses & $6(12 \%)$ & $3(50 \%)$ & $3(50 \%)$ & \\
\hline Half the times & $2(4 \%)$ & $0(0 \%)$ & $2(100 \%)$ & \\
\hline They rarely observe & $2(4 \%)$ & $1(100 \%)$ & $0(0 \%)$ & \\
\hline \multicolumn{5}{|l|}{ Patient-perceived necessity of DOT } \\
\hline It is extremely necessary & $33(66 \%)$ & $13(39.4 \%)$ & $20(60.6 \%)$ & \multirow{3}{*}{0.106} \\
\hline It is moderately necessary & $8(16 \%)$ & $6(75 \%)$ & $2(25 \%)$ & \\
\hline It is unnecessary & $9(18 \%)$ & $6(66.7 \%)$ & $3(33.3 \%)$ & \\
\hline \multicolumn{5}{|l|}{ Patient-perceived quality of DOT } \\
\hline Excellent & $32(64 \%)$ & $17(53.1 \%)$ & $15(46.9 \%)$ & \multirow{3}{*}{0.814} \\
\hline Good & $14(28 \%)$ & $6(42.9 \%)$ & $8(57.1 \%)$ & \\
\hline Average & $4(8 \%)$ & $2(50 \%)$ & $2(50 \%)$ & \\
\hline \multicolumn{5}{|l|}{ Improve DOT } \\
\hline Shorter treatment duration & $4(8 \%)$ & $3(75 \%)$ & $1(25 \%)$ & \multirow{4}{*}{0.278} \\
\hline Improvement in formulation & $11(22 \%)$ & $4(36.4 \%)$ & $7(63.6 \%)$ & \\
\hline More information should be provided on DOTS & $2(4 \%)$ & $2(100 \%)$ & - & \\
\hline Not Applicable & $33(66 \%)$ & $16(48.5 \%)$ & $17(51.5 \%)$ & \\
\hline \multicolumn{5}{|l|}{ Adherence counselling frequency } \\
\hline$<7$ days ago & $7(14 \%)$ & $5(71.4 \%)$ & $2(28.6 \%)$ & \multirow{6}{*}{0.612} \\
\hline$<2$ weeks ago & $2(4 \%)$ & $1(50 \%)$ & $1(50 \%)$ & \\
\hline$<1$ month ago & $9(18 \%)$ & $5(55.6 \%)$ & $4(44.4 \%)$ & \\
\hline $2-3$ months ago & $2(4 \%)$ & $0(0 \%)$ & $2(100 \%)$ & \\
\hline$>3$ months ago & $22(44 \%)$ & $10(45.5 \%)$ & $12(54.5 \%)$ & \\
\hline Never Done & $8(16 \%$ & $4(8 \%)$ & $4(8 \%)$ & \\
\hline \multicolumn{5}{|l|}{ Length of Sessions } \\
\hline$<2$ minutes & $1(2 \%)$ & $1(2 \%)$ & $1(2 \%)$ & \multirow{5}{*}{0.670} \\
\hline $2-5$ minutes & $4(8 \%)$ & $4(8 \%)$ & $4(8 \%)$ & \\
\hline 5 - 10 minutes & $12(24 \%)$ & $12(24 \%)$ & $12(24 \%)$ & \\
\hline$>10$ minutes & $25(50 \%)$ & $25(50 \%)$ & $25(50 \%)$ & \\
\hline Not Applicable & $8(16 \%)$ & $8(16 \%)$ & $8(16 \%)$ & \\
\hline \multicolumn{5}{|l|}{ Improve adherence } \\
\hline Counselling sessions should be done at least once weekly & $5(10 \%)$ & $4(80 \%)$ & $1(20 \%)$ & \multirow{2}{*}{0.348} \\
\hline Counselling sessions should be done at least once monthly & $16(32 \%)$ & $8(50 \%)$ & $8(50 \%)$ & \\
\hline Not applicable & $29(58 \%)$ & $13(44.8 \%)$ & $16(55.2 \%)$ & \\
\hline \multicolumn{5}{|l|}{ Is TB Curable } \\
\hline Yes & $44(88 \%)$ & $23(52.3 \%)$ & $21(47.7 \%)$ & \multirow[t]{2}{*}{0.384} \\
\hline No & $6(12 \%)$ & $2(33.3 \%)$ & $4(66.7 \%)$ & \\
\hline
\end{tabular}




\section{Continued}

\section{Faith in treatment}

Yes

$48(96 \%)$

$24(50 \%)$

$24(50 \%)$

1.000

No

$2(4 \%)$

$1(50 \%)$

$1(50 \%)$

MDR-TB Definition

Patient knows what MDR-TB is

$13(26 \%)$

$10(76.9 \%)$

$3(23.1 \%)$

0.024

Patient doesn't know what MDR-TB is

$37(74 \%)$

$15(40.5 \%)$

$22(59.5 \%)$

\section{MDR-TB Etiology}

Patient knows how MDR-TB arises

Patient doesn't know how MDR-TB arises

$1(2 \%)$
$49(98 \%)$

$1(100 \%)$

0.312

$24(49 \%)$

$25(51 \%)$

\section{Missed dose perception}

A single dose can cause treatment failure

A few missed doses aren't significant

Treatment success only requires at least $50 \%$ adherence

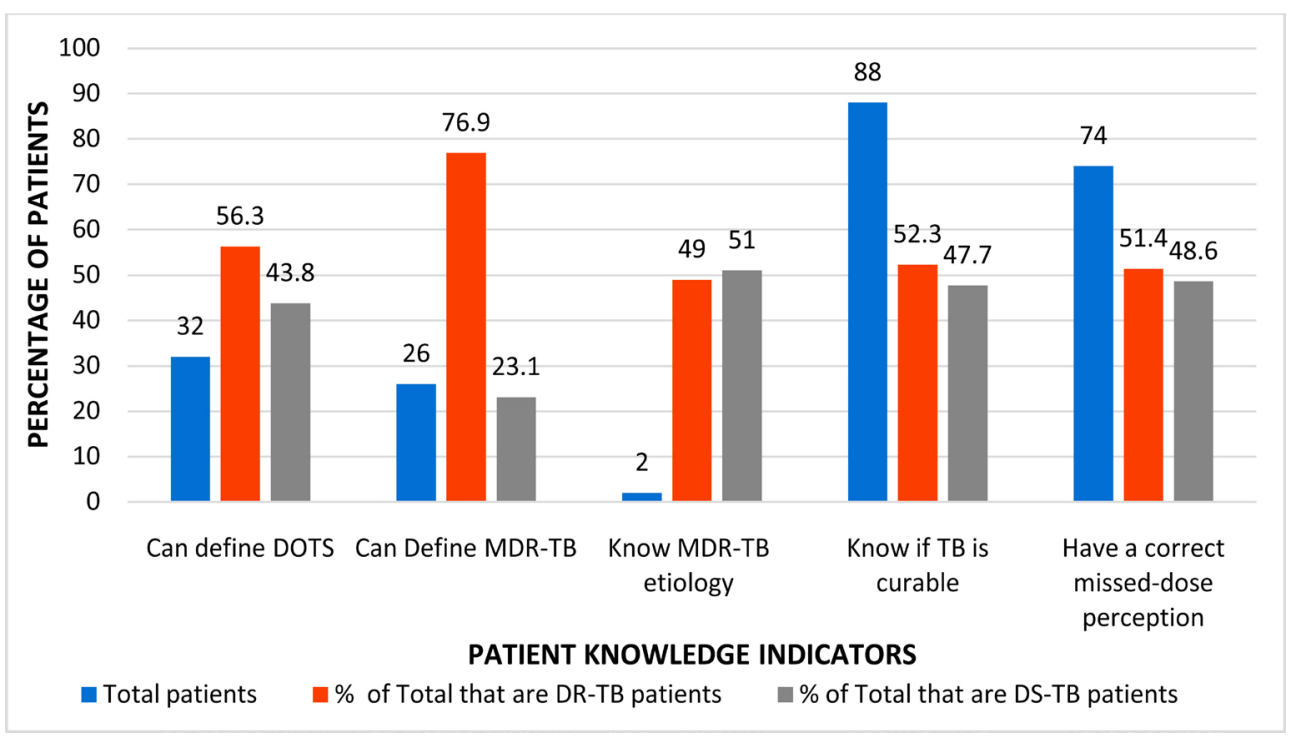

Figure 2. Patient knowledge related quality of DOT adherence counselling indicators.

The patient-perceived quality of DOT adherence counselling indicators revealed that $34 \%$ of the patients $(n=17)$ felt that DOT was moderately important or unnecessary, however $92 \%(n=46)$ rated the DOT that they received as good or excellent. About $34 \%$ of the patients identified aspects that can be modified to improve the DOT quality and similarly, $42 \%$ of patients identified areas of adherence counselling where improvements can be made to the quality (Table 4 , Figure 2). A significant number of MDR-TB (44\%) and DS-TB (57\%) patients would not appropriately define what directly observed therapy (DOT) entails and/or aware of whether tuberculosis is curable (Figure 2). Over half of the patients don't know want to do in case they miss to take a dose of their TB medication (Figure 2). 


\section{Discussion}

\subsection{Discussion of Findings}

The study aimed to determine the quality and factors associated with TB DOTS adherence counselling among hospitalized DR-TB patients and DS-TB patients. We found that the quality of DOT Adherence counselling is sub-optimal in terms of the comprehensiveness and service delivery. The study also found that patients had poor knowledge on basic aspects of DOT and TB treatment and outcomes. A stratified cluster randomized control trial in America also found the inadequacy of the standard DOT adherence counselling as well as improvement in treatment outcomes [19]. Similar studies, also report improvement in treatment outcomes among patients in the adherence-counselling programme [26] [27]. This calls for strengthening quality of adherence counselling in the DOTS programmes particularly in TB programmes in LMIC.

The main driving factors of the quality of DOT adherence counselling identified by this study were patient-related factors and hospital-related factors (Table 2 , Table 3). The main patient-related determinants identified by this study were patient preferences, of which the most significant one was the preference of individual counselling sessions as opposed to group counselling sessions $(74 \%, \mathrm{n}=$ 37). This was because the patients felt that they could disclose any potential problems affecting their adherence more freely in individual counselling sessions as well as ask any relevant questions could potentially be personal. In addition, the majority of the patients however did not have any preferences regarding the age and sex of the counsellors (Table 2) and reasoned that any age or sex is acceptable, provided that the counsellors are professional and competent. The main reasons identified for a lack of adherence was forgetfulness and treatment cessation by the patient upon feeling better (Table 2).

Similar studies, such as a study done in India have also identified patient-related factors that affect the emergence of drug resistant $\mathrm{TB}$, the study found that the main barriers to adherence were drug side effects, a perceived lack of provider support, patient financial constraints, and conflicts with the timing of treatment services, alcoholism and social stigma [15] [28] [29]. Another study done in China used multivariate conditional logistics regression models to identify determinants of MDR-TB and/or adherence to medication which included, previous TB treatment; male sex, high school or lower education degree, unemployment, long distance of residence from the health facility; smoking, poor knowledge regarding MDR-TB, social stigma, among others [29] [30] [31].

These studies are however quite limited because the variables investigated as potential determinants of MDR-TB were only from the patient's perspective and completely neglected any determinants of MDR-TB that could be as a result of the health care providers, such as a lack of adherence counselling or a poor quality thereof. The results of the patient related factors affecting the quality of DOT adherence counselling in this study reinforce the results that were found in the above mentioned studies. This indicated that there is a compelling need for bet- 
ter management particularly through improving medication adherence guidelines.

The study also investigated patient preferences. We found that most patient preferred to take medication at home $(56 \%, \mathrm{n}=28)$ rather than in the hospital. Whilst the others argued that being an in-patient was more beneficial because they had access to free meals at the hospital and reduced negative influences such as taking alcohol, that hinder good adherence and treatment completion.

Several studies such as a study done by Cadosch, et al. have investigated the effects of adherence counselling and DOT on treatment outcomes. The results of that study showed that failure to adhere to anti-TB medication directly affects treatment outcomes [22]. Another study done in 2016 looked at the association between DOT and TB treatment outcomes and found that there was no statistical significance [17]. These studies however did not look at any factors that directly influence the quality of DOT adherence. This study did however investigate the hospital-related factors and found that: majority of the patients found that the DOT schedule was consistent and convenient (Table 3). About $80 \%$ of the patients were counselled in a language that they understand, however $(16 \%$, $\mathrm{n}=8 / 50$ ) were not counselled at all and $74 \%$ felt that the counsellors were friendly and not judgmental. These results reflect that with respect to the hospital related factors, the null hypothesis is satisfied and the quality of the DOT counselling according to these factors is optimal.

This study also used specific indicators to directly measure the quality of the TB DOT adherence counselling (Table 4). The indicators were based on the DOT adherence counselling services itself, patient knowledge after DOT counselling and patients directly rating the DOT counselling (Table 4).

Results that directly reflect on the service itself concluded that $(94 \%, \mathrm{n}=47)$ of the patients received DOT at each or most doses (although some patients revealed that they were allowed to drink the medicines in their rooms without supervision which defeats the purpose of DOT), however only $40 \%$ of the patients were counselled at least 3 months ago, 36\% were counselled at least 1 month ago and $16 \%$ were not counselled at all since being admitted. These results, especially those pertaining to adherence counselling frequency are significantly low and thus provide compelling evidence for the need for improved national standard operating protocols for DOTS and adherence counselling. In addition, results pertaining to the patient-perceived quality of the DOT services were high (Table 4) and acceptable for optimal DOTS quality.

The patients' knowledge as assessed after the patients received DOTS and adherence counselling was however very poor (Table 4). This clearly rejects the null hypothesis and indicates that the quality of DOT counselling as related to patient knowledge is indeed suboptimal. There are no documented studies that directly measured the quality of DOTS or adherence counselling using indicators and thus the results from the indicators could not be compared to any other studies. 


\subsection{Conclusions and Recommendations}

Based on the findings, we conclude that the quality of DOTS counselling for DR-TB as well as DS-TB cases at Katutura Intermediate Hospital is sub-optimal.

The results from the patient-related factors and hospital-related factors reinforced findings from studies previously done that indicate that the quality of DOT adherence counselling in these particular areas is optimal.

The results from the indicators revealed that the patients' knowledge regarding $\mathrm{TB}$ at large is very poor, which in turn reflects that the quality of DOT adherence counselling is sub-optimal. The frequency of adherence counselling was also found to be sup-optimal according to our judgement and the patients' views and recommendations.

Despite the compelling evidence provided by similar studies on the strong association between good DOT adherence counselling and increased treatment outcomes, there are no existing TB DOT adherence counselling protocols nationwide or from the World health organization that may be used to accurately measure the quality of DOT adherence counselling.

The indicators identified in this study may be used to develop national standard operating for DOTS and adherence counselling which can be used to measure and ensure nationwide good quality DOT adherence counselling which is a crucial determinant of the emergence of drug-resistant tuberculosis.

\subsection{Limitations}

This research study was done in Windhoek (which is an urban setting) and therefore, the results are not generalizable to the country's entire population. Furthermore, this study was done on a Namibian population and the results from this study are not necessarily be generalizable for any other population groups.

\section{Conflict of Interest and Funding}

The authors hereby declare that they have no conflicts of interest to disclose. This study did not receive any specific grant from any funding agency in the public, commercial or not-for-profit sectors.

\section{References}

[1] Kulpati, D.D.S. (2005) Multidrug Resistant Tuberculosis (MDR-TB). Journal International Medical Sciences Academy, 18, 104-115.

[2] Hopewell, P.C., Pai, M., Maher, D., Uplekar, M. and Raviglione, M.C. (2006) International Standards for Tuberculosis Care. Lancet Infectious Diseases, 6, 710-725. https://doi.org/10.1016/S1473-3099(06)70628-4

[3] WHO (2016) MDR-TB. Burden, Glob. Treat. Enroll. O N Mdr-tb Outcomes, Treat.

[4] WHO (2015) Global Tuberculosis Report 2015.

[5] MoHSS (2015) Republic of Namibia Ministry of Health and Social Services National Tuberculosis and Leprosy Programme Annual Report: 2014-2015.

[6] Kibuule, D., et al. (2018) Predictors of Tuberculosis Treatment Success under the 
DOTS Program in Namibia. Expert Review of Respiratory Medicine, 12, 979-987. https://doi.org/10.1080/17476348.2018.1520637

[7] van Gorkom, J., et al. (2013) TB Control in Namibia 2002-2011: Progress and Technical Assistance. The Open Infectious Diseases Journal, 7, 23-29.

https://doi.org/10.2174/1874279301307010023

[8] Kibuule, D., et al. (2019) Effectiveness of the Community-Based DOTS Strategy on Tuberculosis Treatment Success Rates in Namibia. International Journal of Tuberculosis and Lung Disease, 23, 441-449. https://doi.org/10.5588/ijtld.17.0785

[9] Stop, T.B. (2006) The Strategy: Building and Enhancing DOTS to Meet the TB Related Millennium Development Goals. WHO, Geneva.

[10] Calderón-Ospina, C. and Bustamante-Rojas, C. (2010) The DOTS Classification Is a Useful Way to Classify Adverse Drug Reactions: A Preliminary Study in Hospitalized Patients. International Journal of Pharmacy Practice, 18, 230-235. https://doi.org/10.1111/j.2042-7174.2010.00039.x

[11] De Riemer, K., et al. (2005) Does DOTS Work in Populations with Drug-Resistant Tuberculosis? The Lancet, 365, 1239-1245. https://doi.org/10.1016/S0140-6736(05)74812-1

[12] Srivastava, S., Pasipanodya, J.G., Meek, C., Leff, R. and Gumbo, T. (2011) Multidrug-Resistant Tuberculosis Not Due to Noncompliance But to Between-Patient Pharmacokinetic Variability. The Journal of Infectious Diseases, 204, 1951-1959. https://doi.org/10.1093/infdis/jir658

[13] Lutge, E.E., Wiysonge, C.S., Knight, S.E., Sinclair, D. and Volmink, J. (2015) Incentives and Enablers to Improve Adherence in Tuberculosis. Cochrane Database of Systematic Reviews, No. 9, CD007952. https://doi.org/10.1002/14651858.CD007952.pub3

[14] Shringarpure, K.S., Isaakidis, P., Sagili, K.D. and Baxi, R.K. (2015) Loss-to-Followup on Multidrug Resistant Tuberculosis Treatment in Gujarat, India: The When and Who of It. PLOS ONE, 10, e0132543.

https://doi.org/10.1371/journal.pone.0132543

[15] Deshmukh, R.D., et al. (2015) Patient and Provider Reported Reasons for Lost to Follow up in MDRTB Treatment: A Qualitative Study from a Drug Resistant TB Centre in India. PLOS ONE, 10, e0135802. https://doi.org/10.1371/journal.pone.0135802

[16] Fanning, A. (2019) Community-Based Directly Observed Therapy Improves Treatment Success. International Journal of Tuberculosis and Lung Disease, 23, 381-382. https://doi.org/10.5588/ijtld.19.0158

[17] Yin, J., Yuan, J., Hu, Y. and Wei, X. (2016) Association between Directly Observed Therapy and Treatment Outcomes in Multidrug-Resistant Tuberculosis: A Systematic Review and Meta-Analysis. PLoS ONE, 11, e0150511. https://doi.org/10.1371/journal.pone.0150511

[18] Boateng, S.A., Kodama, T., Tachibana, T. and Hyoi, N. (2010) Factors Contributing to Tuberculosis (TB) Defaulter Rate in New Juaben Municipality in the Eastern Region of Ghana. Journal of the National Institute of Public Health, 59, 291-297.

[19] Khachadourian, V., Truzyan, N., Harutyunyan, A., Thompson, M.E., Harutyunyan, T. and Petrosyan, V. (2015) People-Centered Tuberculosis Care versus Standard Directly Observed Therapy: Study Protocol for a Cluster Randomized Controlled Trial. Trials, 16, 281. https://doi.org/10.1186/s13063-015-0802-2

[20] Singh, A. and Pant, N. (2014) Adverse Effects of First Line Antitubercular Medicines on Patients Taking Directly Observed Treatment Short Course: A Hospital 
Based Study. International Journal of Medicine and Public Health, 4, 354-358. https://doi.org/10.4103/2230-8598.144063

[21] Deye, N., Vincent, F., Michel, P., Ehrmann, S., Da Silva, D., Piagnerelli, M., Laterre, P.-F., et al. (2016) Changes in Cardiac Arrest Patients' Temperature Management after the 2013 "TTM" Trial: Results from an International Survey. Annals of Intensive Care, 6, 4.

[22] Cadosch, D., Abel zur Wiesch, P., Kouyos, R. and Bonhoeffer, S. (2016) The Role of Adherence and Retreatment in De Novo Emergence of MDR-TB. PLOS Computational Biology, 12, e1004749. https://doi.org/10.1371/journal.pcbi.1004749

[23] Raviglione, M.C. and Uplekar, M.W. (2006) WHO's New Stop TB Strategy. The Lancet, 367, 952-955. https://doi.org/10.1016/S0140-6736(06)68392-X

[24] Huynh, G.H., et al. (2015) Tuberculosis Control Strategies to Reach the 2035 Global Targets in China: The Role of Changing Demographics and Reactivation Disease. BMC Medicine, 13, 88. https://doi.org/10.1186/s12916-015-0341-4

[25] Tran, D.A., Ngo, A.D., Shakeshaft, A., Wilson, D.P., Doran, C. and Zhang, L. (2013) Trends in and Determinants of Loss to Follow Up and Early Mortality in a Rapid Expansion of the Antiretroviral Treatment Program in Vietnam: Findings from 13 Outpatient Clinics. PLoS ONE, 8, e73181. https://doi.org/10.1371/journal.pone.0073181

[26] M'Imunya, J.M., Kredo, T. and Volmink, J. (2012) Patient Education and Counselling for Promoting Adherence to Treatment for Tuberculosis. Cochrane Database of Systematic Reviews, No. 5, CD006591. https://doi.org/10.1002/14651858.CD006591.pub2

[27] Datiko, D.G. (2011) Improving Tuberculosis Control in Ethiopia: Performance of TB Control Programme, Community DOTS and Its Cost-Effectiveness.

[28] Baral, S.C., Aryal, Y., Bhattrai, R., King, R. and Newell, J.N. (2014) The Importance of Providing Counselling and Financial Support to Patients Receiving Treatment for Multi-Drug Resistant TB: Mixed Method Qualitative and Pilot Intervention Studies. BMC Public Health, 14, 46. https://doi.org/10.1186/1471-2458-14-46

[29] Munro, S.A., Lewin, S.A., Smith, H.J., Engel, M.E., Fretheim, A. and Volmink, J. (2007) Patient Adherence to Tuberculosis Treatment: A Systematic Review of Qualitative Research. PLoS Medicine, 4, e238. https://doi.org/10.1371/journal.pmed.0040238

[30] Sagbakken, M., Frich, J.C. and Bjune, G. (2008) Barriers and Enablers in the Management of Tuberculosis Treatment in Addis Ababa, Ethiopia: A Qualitative Study. BMC Public Health, 8, 11. https://doi.org/10.1186/1471-2458-8-11

[31] Zhang, C., et al. (2016) Determinants of Multidrug-Resistant Tuberculosis in Henan Province in China: A Case Control Study. BMC Public Health, 16, 42. https://doi.org/10.1186/s12889-016-2711-Z 


\section{Annexures}

\section{Annexure A: Consent Form}

\section{QUALITY OF DOTS COUNSELLING AMONG PATIENTS WITH MDR TUBERCULOSIS}

Team Leader: Dan Kibuule (dkibuule@unam.na) and Taati Shikongo

PURPOSE OF STUDY: The School of Pharmacy is carrying out an assessment quality of counselling among patients with drug resistant tuberculosis with a focus on improving the counselling services in multidrug resistant tuberculosis. Your participation in this research will help us to understand the determinants of quality DOTS counselling from a patients perspective and how the capacity and efficiency could be improved.

\section{STUDY PROCEDURE}

I agree to participate in the study as a respondent to the interviewer-administered questionnaire; I understand that my personal records will be used confidentially for this study.

\section{BENEFITS}

I will benefit from the study by getting some information the quality of DOTS counselling patients receive at the facility and strategies to improve it.

\section{Risks}

My information will not be used for any other purposes other than this stay. My records will remain confidential and be handled in professional manner.

\section{Reimbursement}

I will not be paid for participating in the study.

\section{RIGHT TO REFUSE OR WITHDRAW}

The use of my information is entirely voluntary and can be freely withdrawn without anything levied on me.

\section{CONFIDENTIALITY}

The data collected in this study will be kept confidential and used only for research purposes. My identity will be kept confidential as far as the law allows. My name shall not appear on any forms. All information will be kept on coded forms.

\section{STATEMENT OF CONSENT}

has described to me what is going to be done, the risks and benefits involved. I do understand that my participation is entirely voluntary and my identity will remain anonymous. I also understand by signing this consent form, I do not waive any of my legal rights but merely indicate that I 
have been informed about the research study in which I am voluntarily agreeing to participate.

A copy of this form will be provided to me.

Signature of participant Date

Signature of interviewer Date

\section{Annexure B: Patient's Questionnaire}

QUALITY OF TB DOTS ADHERENCE COUNSELLING SURVEY

Aim of Study. To measure the quality of the DOTS Adherence Counselling and improve it make the appropriate recommendations to improve it

Researcher: Taati Shikongo and Dan Kibuule, School of Pharmacy, UNAM

Please answer the questions as truthfully as possible and CHOOSE THE MOST RELEVANT ANSWER BY CHECKING (MARK WITH AN X) THE APPROPRIATE BOX OR SPECIFY YOUR ANSWER WHERE APPLICABLE

Part A: Social demographic characteristics of the respondents

1.1. What is your gender?

Male

Female

1.2. What is your age in years?

1.3. What is your highest level of education?

None $\square \quad$ Primary $\square \quad$ Secondary $\square \quad$ Tertiary $\square$

Part B: Awareness on DOTS adherence counselling

1.4. Do you know what DOTS (Direct-Observed treatment therapy) is and why it is done?

Yes $\square \quad$ No $\square$

1.5. How often do the health care providers (nursing staff) observe you while you take your medicines?

At each dose

At most doses $\square$

Half the times

They rarely observe $\square$

They never observe

1.6. Do you think DOTS is necessary in helping you improve your medication adherence?

It is extremely necessary $\square \quad$ It moderately necessary

It is unnecessary $\square$

1.7. Are the times that DOTS is done consistent (at the same time every day)?

Yes $\square \quad$ No $\square$ 
1.8. Are the set times that DOTS is done convenient for you? Yes No $\square$

1.9. Do you think that your adherence would improve if you were at home as opposed to being in the hospital?

Yes No $\square$

1.10. How would you rate the current DOTS which you receive? Excellent Good $\square$ Average $\square$ Poor $\square$ Very Poor $\square$

1.11. How would you improve the current DOTS?

1.12. Any additional comments you have about the DOTS programme?

\section{Part C: ADHERENCE COUNSELLING}

2.1. When was your last adherence counselling session done?

$$
\begin{array}{lll}
<7 \text { days ago } \square & <2 \text { weeks ago } \square & <1 \text { month ago } \square \\
2-3 \text { months ago } \square & >3 \text { months ago } \square
\end{array}
$$

2.2. How long are the adherence counselling sessions on average?
$<2$ minutes $\square$
2 - 5 minutes $\square$
5 - 10 minutes $\square$
$>10$ minutes

2.3. Do you prefer adherence counselling sessions that are done in groups or individually?

Individually $\square \quad$ In Groups $\square$

2.4. Are the adherence counselling sessions done in a language that you clearly understand?

Yes

No $\square$

2.5. Are the adherence counsellors judgemental?

Yes

No $\square$

2.6. Do the counsellors provide an environment where you can openly and comfortably disclose issues such as lack of adherence?

Yes

No $\square$

2.7. Would you prefer a counsellor that is the same sex as you? Yes $\square \quad$ No $\square$

The Gender is irrelevant

2.7.1. Give a reason for your answer (if yes/no)

2.8. What age would you prefer the counsellor to be?

Younger than you

Older than you $\square$
The same age as you $\square$

The Age is irrelevant $\square$ 


\subsubsection{Give a reason for your answer}

2.9 In your opinion, is TB completely curable?

Yes $\square$

No $\square$

2.10. Are you confident that the treatment will work if you maintain good adherence?

Yes $\square$

No $\square$

2.11. What is Multi-Drug Resistant Tuberculosis (MDR-TB) and how does it arise?

2.12. What is your perception on missed doses?

1 single missed dose can cause treatment failure

A few missed doses aren't significant

Treatment success only requires at least $50 \%$ adherence $\square$

Missed doses don't really affect treatment success

2.13. How would you improve the current adherence counselling methods?

2.14. Any additional comments you have about adherence counselling?

THANK YOU FOR YOUR PARTICIPATION!!

Can you try to include these questions from the Morisky scale

Table A. Characteristics on adherence to diabetic medication $(\mathrm{N}=96)$.

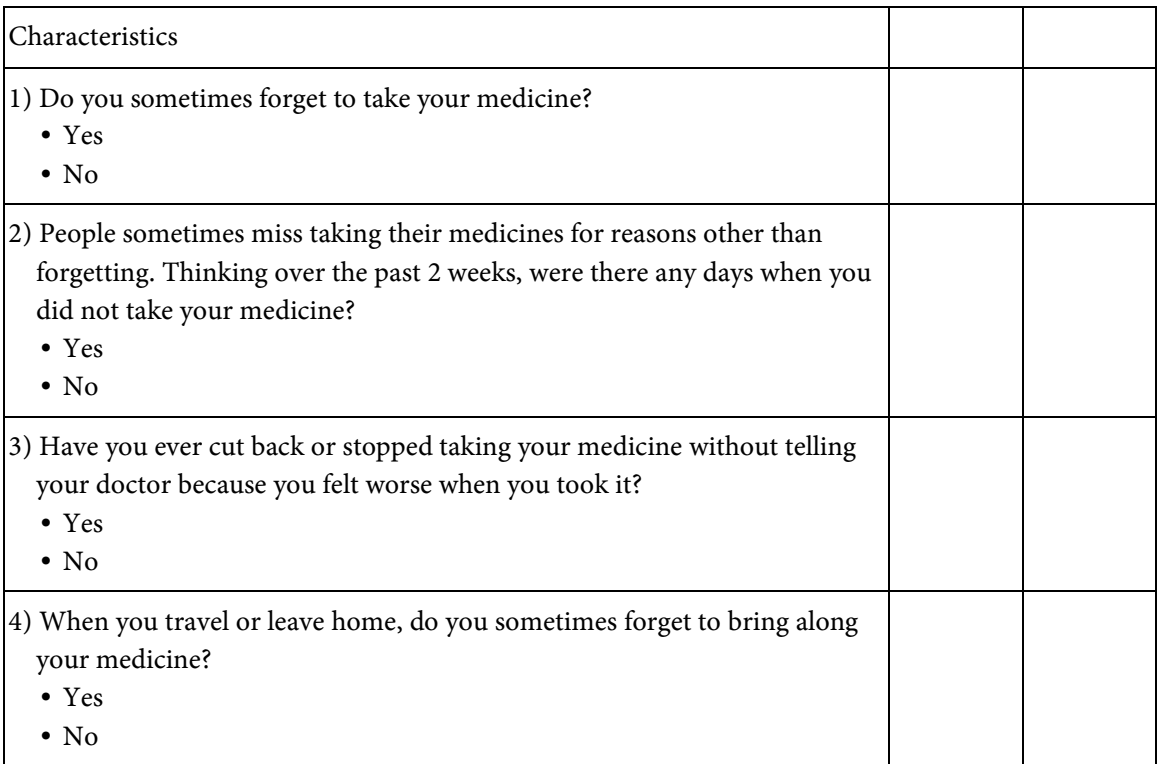




\section{Continued}

\begin{tabular}{|l|l|l|}
\hline $\begin{array}{l}\text { 5) Did you take all your medicines yesterday? } \\
\text { - Yes }\end{array}$ & \\
\hline No & & \\
6) When you feel like your symptoms are under control, do you sometimes & & \\
stop taking your medicines? & & \\
- No & & \\
\hline 7) Do you ever feel hassled about sticking to your treatment plan? & \\
- Yes & & \\
8) Ho & & \\
a) Never & & \\
b) Once in a while & & \\
c) Sometimes & & \\
d) Usually & & \\
e) All the time & & \\
\hline
\end{tabular}

